\title{
Selective Removal of Necrotic Dentin in Primary Teeth Using Laser Irradiation: One-Year Clinical Evaluation of Composite Restorations
}

\author{
Silvana Aparecida Fernandes Polizeli ${ }^{{ }^{*}}$, Fabiana Almeida Curylofo-Zotti ${ }^{2}$, Rodrigo Alexandre Valério ${ }^{1}$, \\ Mariana Alencar Nemezio', Aline Evangelista Souza-Gabriel'², Maria Cristina Borsatto', Silmara Aparecida \\ Milori Corona ${ }^{2}$
}

${ }^{1}$ Clinical Pediatric Dentistry Department, Ribeirão Preto School of Dentistry, São Paulo University, Brazil ${ }^{2}$ Restorative Dentistry Department, Ribeirão Preto School of Dentistry, São Paulo University, Brazil

\author{
*Correspondence to \\ Silmara Aparecida Milori Corona, \\ Café Avenue, s/n Monte Alegre, \\ Ribeirão Preto, SP, 14040-904 \\ Brazil, \\ Phone: +55 16 3315-4075; \\ Fax: +55 $163315-0999$ \\ Email: silmaracorona@forp.usp.br
}

Published online February 25 2019

\begin{abstract}
Introduction: This study aimed to evaluate the child's salivary cortisol levels, clinical performance and marginal adaptation of restorations after selective removal of necrotic dentin in primary teeth using Er: YAG laser irradiation.

Methods: A double-blind clinical study was performed in children at 7-10 years. Children who had at least 2 teeth with carious lesions involving the occlusal and proximal surfaces of primary molars counterparts were selected. Removal of necrotic dentin was performed by 2 methods: Er: YAG laser irradiation and bur-preparation. Cortisol levels $(n=24)$ was evaluated by ELISA. Clinical analysis $(n=20)$ was performed after the restorations polish, 6 and 12 months after restorative procedure using United States Public Health Service (USPHS) method and photographs. Scanning electron microscopy (SEM) was used to analyz the marginal gap formation $(n=20)$. The analysis of the data was performed by $95 \%$ confidence interval, Shapiro-Wilk test, Friedman and Wilcoxon post hoc tests $(\alpha=5 \%)$.

Results: Cortisol levels were higher during selective removal of necrotic dentin, regardless of the method used $(P>0.05)$. After 12 months, there was no evidence of the difference in the restorations performed on cavities prepared by both methods. SEM analysis revealed that the laser-irradiated teeth showed $10 \%$ of gaps in the full extent of restoration. For bur-prepared teeth, $20 \%$ of gaps were found at the cavosurface margin.

Conclusion: The salivary cortisol levels on children that received Er: YAG laser irradiation for removal the necrotic dentin was similar to the control group. Class II restorations evaluated after 1 year period did not suffer interference by the use of Er: YAG laser irradiation.

Keywords: Lasers; Dental restoration; Dental caries; Stress; Primary teeth
\end{abstract}

\section{Introduction}

The selective (or partial) caries removal in primary teeth has been shown as an advantageous technique, considering that this treatment inactivates carious lesions and reduces the levels of cariogenic microorganisms in dentin. ${ }^{1,2}$ The outer zone has irregular crystals and irreversibly denatured collagen, which should be completely removed. Unlike, internally the caries-affected dentin has reduced reticular fibers and apatite crystals flakes cross-linked with the fibers. ${ }^{3}$

It is known that dental procedures cause stress and fear on children ${ }^{4,5}$ mainly due to the use of rotating drills (diamond or tungsten, or both) that generate heat, noise, and pressure. ${ }^{6}$ The cortisol also called the "stress hormone," is an interesting tool to be the most important synthesized glucocorticosteroid in the cortex of the adrenal gland. It has major anti-inflammatory and immunosuppressive properties, inhibiting the formation of lymphocytes and inducing lymphatic tissue hyperplasia ${ }^{7}$ and has been evaluated in studies of stress and fear. ${ }^{8}$ The salivary cortisol is an indicator of free cortisol (biologically active) in human serum, and the analysis of salivary cortisol levels is a noninvasive and easy technique to perform during dental practice. ${ }^{9-12}$

The stress during a restorative dental treatment, especially in pediatric patients, may be considerably reduced with the use of laser irradiation. ${ }^{6}$ Laser technology eliminates discomfort caused by noise and vibration during the use of the conventional rotary instruments, reducing the need of local anesthesia, ${ }^{13-15}$ being well

Please cite this article as follows: Polizeli SAF, Curylofo-Zotti FA, Valério RA. Selective removal of necrotic dentin in primary teeth using laser irradiation: one-year clinical evaluation of composite restorations. J Lasers Med Sci. 2019;10(2):108-116. doi:10.15171/jlms.2019.18. 
accepted by patients. ${ }^{14}$

The Er: YAG laser promotes effective ablation of carious tissues, ${ }^{16}$ by means of water evaporation resulting in micro-explosions in the mineralized tissue. ${ }^{17}$ Treatment with Er: YAG laser does not affect $\mathrm{Ca}, \mathrm{K}, \mathrm{Mg}, \mathrm{Na}$, and $\mathrm{P}^{18}$ and was similar to bur preparation in carious tissue removal of primary teeth ${ }^{19}$ being considered safe for cavity preparation. In addition, restorations performed with Er: YAG laser irradiation were clinically acceptable, following the modified United States Public Health Service (USPHS) criteria. $^{19,20}$

Due to the lack of well-designed randomized trials assessing the children stress during caries removal using laser irradiation, as well as the durability of restorations, the purpose of this study was to evaluated salivary cortisol levels, clinical performance of restorations and marginal adaptation of the replica of restorations, after selective removal of necrotic dentin in primary molars using Er: YAG laser irradiation. The null hypotheses tested were: (1) Child's salivary cortisol level is not influenced by the method for selective removal of necrotic dentin; (2) The method used for caries removal does not influence the longitudinal performance of class II composite restorations in primary molars.

\section{Methods}

\section{Study Design}

This study analyzed the method used in selective removal of necrotic dentin, in 2 levels: (1) Er: YAG laser (250 $\mathrm{mJ} / 4 \mathrm{~Hz}$ ) and (2) bur-preparation method (drills at lowspeed rotation). The experimental sample consisted of 24 children and 48 primary molars that had dentin carious lesions on occlusal and proximal surfaces. The study was a double-blind randomized clinical trial design, that were analyzed: clinical assessment of salivary cortisol levels during the selective removal of necrotic dentin by enzyme-linked immunosorbent assay (mol/L), clinical evaluation of restorations by modified USPHS criteria, qualitative evaluation of photographic restoration and quantitative analysis of marginal adaptation of the replica of the restoration by scanning electron microscopy (SEM).

The volunteer's parents or keepers received all information about the study and the possibility to withdraw the research at any time. Then, a consent term was signed.

\section{Recruitment}

Calculation of patient recruitment was suggested in the findings of Valério et al. ${ }^{19}$ Through the website https:// www.sealedenvelope.com (Sealed Envelope Ltd.) by means of a power calculator, it was used the equivalence trial with the following parameters: $\alpha=5 \%$, the power of $90 \%$ and equivalence limit of $15 \%$, resulting in 20 children.

It was examined 1.115 children, of both genders aged 7 to 10 years old. It was performed clinical and radiographic examination using digital radiography sensor (CDR Elite,
Fona, São Paulo, SP, Brazil) with positioner. The inclusion criteria were: 2 dentin carious lesions on occlusal and proximal surfaces of primary molars counterparts (medium and deep cavities), with less than half of the root resorbed and vital pulps, and lack of restorative materials. $^{21}$

Seventy-one children were selected for this study. Of these volunteers, 47 refused to participate, thus, 24 children were selected and cortisol analysis was performed. Four children did not return after 7 days for polishing of restoration, thus, 20 children $(n=20)$ were included in the clinical follow-up. Figure 1 represents the CONSORT diagram, where the stages of monitoring to the subjects from the beginning to the final condition are reported.

Firstly children received dental prophylaxis followed by the clinical examination. Children received complete dental treatment depending on their need, involving all areas of dentistry. Calibration of the three clinical examiners was done across the analysis of dental manikins that had their teeth restored with composite resin (Kappa test: $\mathrm{A}$ and $\mathrm{B}$ interexaminer agreement = $0.92, \mathrm{~A}$ and $\mathrm{C}$ interexaminer agreement $=0.89$ and $\mathrm{B}$ and $\mathrm{C}$ interexaminer agreement $=0.94)$.

Selective Removal of Necrotic Dentin

Selected children had their names numbered to order their treatment using the website http:// randomnumbergenerator.intemodino.com/pt/, therefore teeth were randomly directed toward the groups: (1) Er: YAG laser irradiation or (2) bur-preparation method (drill at low-speed) by the coin toss. The treatments were performed in separate sessions, with an interval of 7 days between sessions.

The child was carefully anesthetized with topical anesthetic (EMLA, Astrazeneca Laboratory, Cotia SP, Brazil), followed by the application of a local anesthetic solution. After anesthesia, a period of 15 minutes was waited, allowing cortisol levels to return to normal values.22 Duringthis waiting period, the color of the composite resin was selected using a color scale $(3 \mathrm{D}$ color scale, Vita Ltda, Petrópolis, RJ, Brazil). The dental operative field was isolated with a rubber dam (Madeitex, São José dos Campos, SP, Brazil) using different clamps (Duflex, SSWhite, Juiz de Fora, MG, Brazil) according to primary molar's morphology. After 15 minutes, the selective removal of necrotic dentin was performed in the primary molar of one hemiarch (experimental) using Er: YAG laser irradiation and drills on the contralateral primary molar (control).

The parameters of Er: YAG laser (Fidelis Er III, Fotona, Ljubljana, Slovenia) used in this study were: MSP mode, with a pen (R02) at the noncontact mode, focal distance of $7 \mathrm{~mm}$, pulsed energy of $250 \mathrm{~mJ}$, frequency of $4 \mathrm{~Hz},{ }^{19}$ output beam diameter of $0.9 \mathrm{~mm}$, energy density of $39 \mathrm{~J} /$ $\mathrm{cm}^{2}$, and under water spray $(6 \mathrm{~mL} / \mathrm{min})$. 


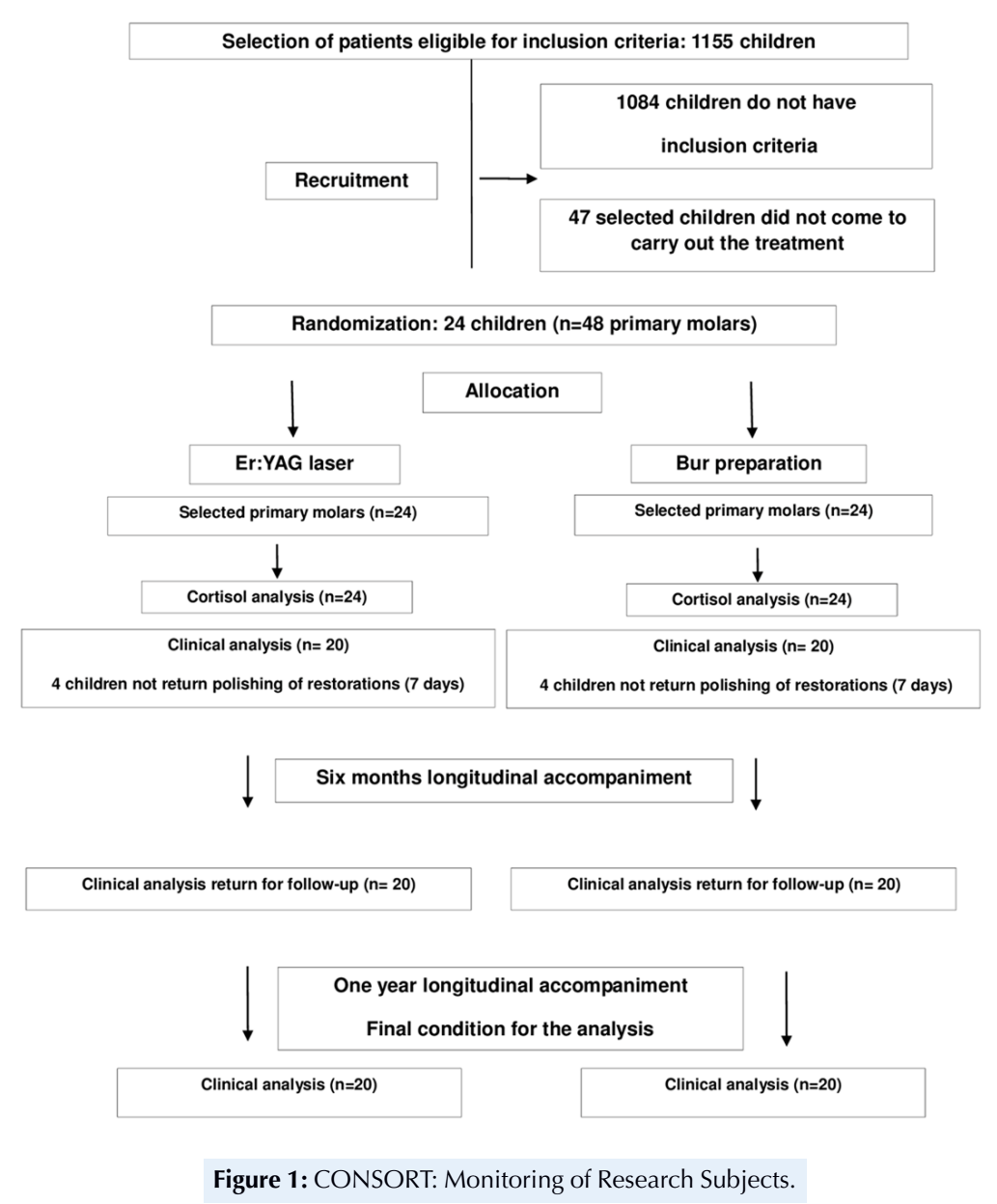

Spherical carbide drills (KG Sorensen, Barueri, SP, Brazil), mounted in low-speed handpiece (contra-angle 1:1 L micro-series, Bier-Air Medical Technologies, Switzerland), compatible with the cavity size, were used for selective removal of necrotic dentin in control group. Using high-speed handpiece (contra-angle 1:5 L microseries, Bier-Air Medical Technologies, Switzerland) the access to caries lesions was performed with spherical diamond drills (KG Sorensen, Barueri, SP, Brazil) compatible with the cavity size.

The selective removal of necrotic dentin was initiated in the superficial layer of infected dentin from the surrounding walls of primary molars using either the Er: YAG laser irradiation or drills. The affected dentin, which is susceptible to remineralization and resistant to curettage was left in the pulpal wall. ${ }^{3}$ Selective removal of necrotic dentin was checked with a probe and evaluated based on clinical criteria of consistency and texture. ${ }^{23}$ Only the incomplete removal of the carious tissue from the surrounding walls was verified according to the clinical hardness criteria, ${ }^{24}$ thus, the curettes \#11, \#11 ${ }^{12}$, and \#12 (Duflex, SSWhite, Juiz de Fora, MG, Brazil) were used to supplement the total removal, whenever necessary for both groups.
Restorative Treatment

Indirect pulp cap was performed in deep cavities using calcium hydroxide cement (Dycal; Dentisply Indústria e Comércio Ltda, Petrópolis, RJ, Brazil), followed by glass ionomer cement (Ketac Molar; 3M, São Paulo, Brazil). Just glass ionomer cement (Ketac Molar; 3M, São Paulo, Brazil) was used in cavities classified as medium.

Acid conditioning was performed with $35 \%$ phosphoric acid gel for 15 seconds in enamel and 7 seconds in dentin, ${ }^{25}$ preceded by washing the cavity for 1 minute. Adhesive single bond universal (3M ESPE, São Paulo, SP, Brazil), São Paulo, SP, Brazil) was applied in 2 layers, interspersed by an air spray for 5 seconds, and light cured (1200 mW/ $\mathrm{cm}^{2}$; Gnatus, Ribeirão Preto, SP, Brazil) following the manufacturer's instructions.

Restorations were performed using Tofflemire matrix band (Golgran, São Caetano do Sul, SP, Brazil) and stainless steel matrix, stabilized by a wooden wedge. As the purpose of returning the ideal anatomical form to the primary molars, was applied the composite resin (Filtek Z350; 3M ESPE, Saint Paul, MN, USA) using the incremental technique being light cured for 20 seconds.

Diamond burs (KG Sorensen, Cotia, SP, Brazil) were used to performed the occlusal adjustment of the 
restorations with the aid of carbon paper (AccuFilm, Parkell, Farmingdale, NY, USA). Children returned after 7 days to final polish of the restorations. ${ }^{19,20}$

\section{Evaluation of Salivary Cortisol}

Salivary cortisol levels evaluated child's stress during selective removal of necrotic dentin. Saliva samples were collected using Salivette ${ }^{\circledR}$ system (Salivette TM, Inc. Sarstedt, Nümbrecht, Germany) before the procedure in the child's home (baseline) and during the selective removal of necrotic dentin: with bur (conventional method) or with Er: YAG laser irradiation.

At the baseline, the saliva collection in the child's residence was performed by the mother or guardian previously oriented by the researcher. The Salivette ${ }^{\circledR}$ system containing a cotton roller tied by a thread and a collecting tube was delivered for the parent/guardian of the child. The cotton roller was placed in the sublingual region of the child, remaining in the mouth for 3 minutes and, subsequently, inserted into the collecting tube and stored in the refrigerator $\left(-20^{\circ} \mathrm{C}\right)$ to avoid bacterial growth in the specimen. It was recommended for patients to avoid eating foods that contain caffeine and acid juices that can affect the salivary $\mathrm{pH}$ on the day before and on the day of the appointment, as well as, do not brush your teeth within the thirty minutes that precede the collect of the saliva.

On the day of the appointment, the collection of saliva was performed after the teeth were isolated. During the removal of dentin carious lesions by bur or Er: YAG laser irradiation, a cotton roller was placed in the sublingual region of the child remaining in the mouth for 3 minutes. After, the roller was inserted into the collecting tube, stored in the refrigerator and then, the restoration was performed. When the procedure ended, the samples were centrifuged (Biosystems, São José dos Pinhais, Paraná, Brazil) at $3000 \mathrm{rpm}$ for 15 minutes for saliva extraction and removes mucins and other particulate matter which may interfere with antibody binding and affect results, so, the analysis of salivary cortisol $(\mathrm{nmol} / \mathrm{L})(\mathrm{n}=24)$ was performed in duplicate by immunoenzymatic assay (Salivary Cortisol ELISA Assay Kit, Salimetrics LLC, PA, USA). The reagents were prepared according to the manufacturer's instructions and $25 \mu \mathrm{L}$ of saliva samples were pipetted into appropriate wells. After incubation, unbound components were washed away. Bound cortisol enzyme conjugate was measured by the reaction of the horseradish peroxidase enzyme to the substrate tetramethylbenzidine (TMB). This reaction produced a blue color. A yellow color was formed after stopping the reaction with an acidic solution. The optical density was read on a standard plate reader at $450 \mathrm{~nm}$ and the concentrations were determined using data reduction software. To obtain the final cortisol concentration was multiplied the concentration of the diluted sample by the dilution factor. The amount of cortisol enzyme conjugate detected was inversely proportional to the amount of cortisol present in the sample.

Clinical and Photographic Evaluation of the Restorations This analysis was performed at different times: after 7 days of the restorative procedure (after the polishing), 6 months and after 1 year of the restorative procedure.

Three examiners with professional experience (SAMC, MAN, FACZ), performed the clinical analysis), according to the modified USPHS criteria, ${ }^{19,20,26}$ which included the analysis of retention, marginal discoloration, marginal adaptation, axial contour, and secondary caries. Restorations were classified as Alpha - restorations in perfect conditions; Bravo - restorations with small failures, but clinically acceptable; and Charlie - restorations with relevant failures, needed to be replaced (Table 1).

After restorations polish, 6 and 12 months period, photographs were taken with a digital camera (Canon EOS Rebel T2i 18.0 Megapixels, Canon, Tokyo, Japan)

SEM Analysis by Means of the Restoration's Replica After the restoration's polish (7 days), 6 months and 1 year period a molding with addition-cured silicone (Express XT, 3M ESPE, Germany) was performed. Molds were disinfected with chlorhexidine $2 \%$ spray, and then, were performed models using epoxy resin (Buehler, SC, Brazil).

The replicas of the restorations were fixed in stubs, metalized with a gold overlay and analyzed by SEM (Zeiss, EVO 50, Cambridge, UK) under 20× magnification. Marginal sealing of the occlusal surface was determined by verifying the presence of irregularities and gaps found in the performed restorations. Non-judgeable parts and artifacts were excluded. Images were analyzed by a calibrated examiner blinded for experimental groups. Radiographic control after one year was not performed

Table 1. Modified USPHS Criteria Performed for Evaluation of the Restorations

\begin{tabular}{|c|c|c|}
\hline Category & Score & Criteria \\
\hline \multirow{2}{*}{ Retention } & Alpha & Presence of restorative material \\
\hline & Charlie & Absence of restorative material \\
\hline \multirow{3}{*}{$\begin{array}{l}\text { Marginal } \\
\text { discoloration }\end{array}$} & Alpha & Absence of marginal discoloration \\
\hline & Bravo & Slight marginal discoloration \\
\hline & Charlie & Visible marginal discoloration \\
\hline \multirow{3}{*}{$\begin{array}{l}\text { Marginal } \\
\text { adaptation }\end{array}$} & Alpha & Perfectly adapted \\
\hline & Bravo & Visible edge, but clinically acceptable \\
\hline & Charlie & Clinical failure \\
\hline \multirow{2}{*}{ Axial contour } & Alpha & $\begin{array}{l}\text { Continuous with existing tooth from } \\
\text { proximal embrasures }\end{array}$ \\
\hline & Bravo & $\begin{array}{l}\text { Sightly under or over contoured, not } \\
\text { continuous }\end{array}$ \\
\hline \multirow{3}{*}{$\begin{array}{l}\text { Secondary } \\
\text { caries }\end{array}$} & Charlie & Moderate under or over contoured \\
\hline & Alpha & No presence of carious lesions \\
\hline & Charlie & Presence of carious lesions \\
\hline
\end{tabular}


considering the recommendations made by the Ethics Committee, which requested that radiographic evaluation should only be performed in cases in which clinical examination failures had been observed. Figure 2 shows a photomicrograph of the replica of the restoration.

\section{Statistical Analysis}

The statistical data obtained by salivary cortisol levels were performed by Shapiro-Wilk test, showing nonnormal sample distribution. Sequentially, Friedman test and Wilcoxon post hoc test were conducted at a significance level of 5\%. For the modified USPHS criteria, descriptive statistics and 95\% confidence intervals were built to proportions of all groups and experimental periods. For the SEM analysis, marginal gaps found on the restorations were expressed as a percentage. Three calibrated examiners (kappa score $>0.80$ ) were blinded from information regarding the experimental groups. Statistical analyses were performed using the SPSS software for Windows, version 19.0 (SPSS Inc., Chicago, IL, USA).

\section{Results}

The results of the salivary cortisol levels are described in Table 2. The salivary cortisol levels were higher during selective removal of necrotic dentin independently of the used method. Salivary cortisol levels obtained during dentin caries removal with Er: YAG laser irradiation was similar to those obtained by bur preparation (drills at low-speed).

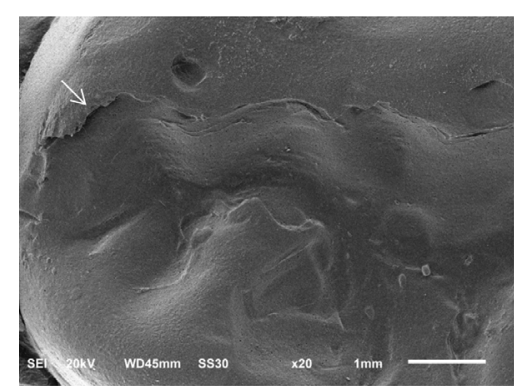

Figure 2. Photomicrograph of replica of the restoration. Arrows indicate the presence of gaps between enamel and composite restoration.

Table 2. Mean (SD) of Salivary Cortisol Levels (mmol/L) Obtained During the Selective Removal of Necrotic Dentin in Class II Cavities of Deciduous Molars $(n=24)$

\begin{tabular}{lc}
\hline Collection Period & $\begin{array}{c}\text { Salivary Cortisol Levels } \\
(\mathbf{n m o l} / \mathbf{L})\end{array}$ \\
\hline Before procedure (baseline) & $0.759(0.571)^{\mathrm{b}}$ \\
$\begin{array}{l}\text { During selective removal of necrotic dentin } \\
\text { using Er:YAG laser }\end{array}$ & $2.253(1.427)^{\mathrm{a}}$ \\
$\begin{array}{l}\text { During the removal of carious lesion by } \\
\text { conventional method }\end{array}$ & $2.705(1.842)^{\mathrm{a}}$ \\
\hline
\end{tabular}

Same letters indicate statistical similarity $(P=0.05)$.
The results of clinical analysis using the modified USPHS criteria showed that there was no evidence of the difference for retention, marginal adaptation, discoloration and secondary caries for restorations performed on class II restorations prepared by both methods. In the analysis of 12 months, one restoration prepared with bur was lost. Table 3 showed a non-expressive number of alterations of the marginal adaptation in restorations of cavities prepared by both methods. Figure 3 shows representative photographs of treatments.

The qualitative SEM analysis of the restoration's replica showed that there was no difference between baseline and 6 months period. After 12 months, the laser-irradiated teeth showed $10 \%$ of gaps in the full extent of restoration. For those prepared with drills, $20 \%$ of gaps were found at the cavosurface angle (Figure 4).

\section{Discussion}

The null hypothesis that there were no differences in salivary cortisol levels of children during the selective removal of necrotic dentin using drills or Er: YAG laser irradiation was accepted. Er: YAG laser removed necrotic dentin by the ablative process because its wavelength $(2.94 \mu \mathrm{m})$ promotes water absorption, leading to micro explosions, evaporation of water content, and consequently, expansion and ejection of the material. ${ }^{17}$ Laser therapy becomes possible the tissue removal without mechanical contact with the dental substrate, thus avoiding heating the remaining structures. Laser irradiation does not promote vibration, pressure or discomfort during the removal of carious lesions, overcoming the children drill phobia., ${ }^{4,19}$

In this study, it was used an electric motor with electromagnetic induction system with $40000 \mathrm{rpm}$ and $2.5 \mathrm{~N}-\mathrm{cm}$ torque. This system differs from the conventional handpiece system because has a pneumatic system with $20000 \mathrm{rpm}$ and $1.2 \mathrm{~N} . \mathrm{cm}$ torque. The electric motor allowed the removal of carious lesions with less pressure and noise, which probably provided a similar comfort to that delivered by Er: YAG laser irradiation. Our findings suggest that dental treatment can increase cortisol levels in children, and not only using specific methods for dentin caries removal. The knowledge of this stressful time can be useful to dental professionals, helping to prepare the children for this moment. These findings were also founded by Akyuz et al. ${ }^{27}$ In addition, caries-affected dentin remained in the pulp and axial walls are able of remineralization and should not be completely removed. ${ }^{3,28}$

In this study, the evaluation of salivary cortisol level was used to analyze children responses to stress during removal of carious lesions. Although there are other physiological measures (including heart rate, oxygen saturation, blood pressure, vagal tonus, glucose, catecholamine, and other hormones), they are more invasive and may have not 


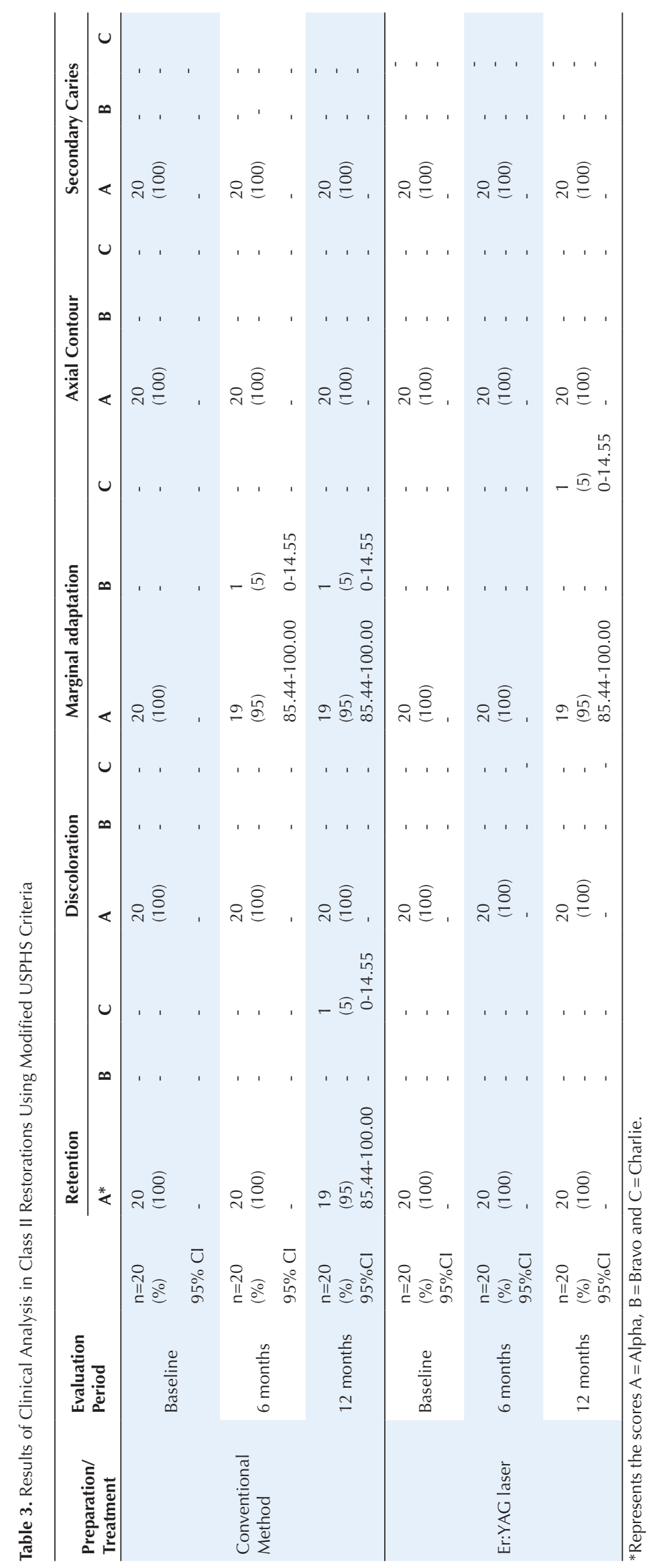



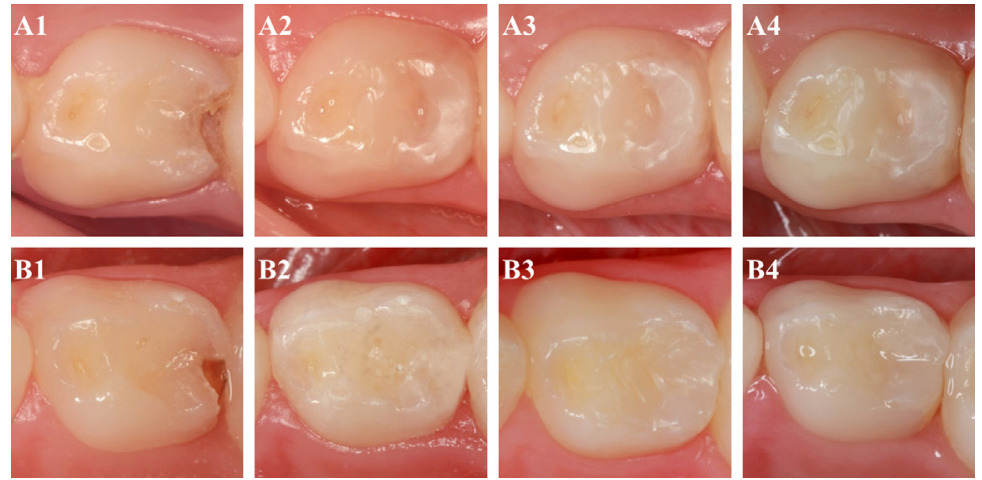

Figure 3. Caries Removal by Conventional Method (A) Er:YAG laser (B). A1: dentin carious lesion on the occlusal and proximal surfaces of a primary molar, A2: initial aspect of restoration (baseline), A3: restoration after 6 months, A4: restoration after 12 months. B1: dentin carious lesion on the occlusal and proximal surfaces of a primary molar; B2: initial aspect of restoration (baseline), B3: restoration after 6 months; B4: the restoration after 12 months.

specificity for the responses to stress during the evaluated procedures. In many cases, to collect blood it is not a feasible alternative; sometimes it is still undesirable, especially in pediatric patients. The evaluation of salivary cortisol offers the opportunity to collect samples without the stress stimulus, which is essential for basal cortisol samples (baseline). ${ }^{29}$

Salivary cortisol levels obtained prior to dental treatment (baseline) had lower values than those obtained during the selective removal of necrotic dentin. These data corroborate the findings found by Yfanti et $\mathrm{al}^{5}$ and Kandemir et $\mathrm{al},{ }^{30}$ in which dental treatment also stimulated the hypothalamus-pituitary-adrenal axis, promoting increased salivary cortisol levels during removal of carious lesions. Basal cortisol levels obtained in this study were similar to normal levels, for children with 4 to 10 years. ${ }^{31}$

In the present study, a factor that may have contributed to the lack of difference in cortisol levels between the methods of caries removal may be that few children exhibited an anxious behavior. Recently, Curcio et $\mathrm{al}^{32}$ reported that only uncooperative children presented high levels of salivary cortisol prior to and shortly after the dental appointment.

The null hypothesis that the method used for caries removal does not influence the longitudinal performance of composite restorations in primary molars was also accepted. Results showed no differences in the evaluated criteria after a 1 year period, independent of the method used for selective removal of necrotic dentin, using to the modified USPHS criteria and photographic evaluation. This may have occurred due to the fact that both methods have promoted proper sealing of the cavity. ${ }^{19,20}$ The success of minimally invasive treatment is given by the ability of the restorative material to promote proper sealing of the dentine, remaining intact and adhered to the tooth surface overtime. ${ }^{33}$ Er: YAG laser for caries removal showed similar results to drills when used in class I cavities. ${ }^{19,20}$

According to Hamidi et $\mathrm{al}^{34}$ restorations performed on laser-prepared cavity showed acceptable clinical performance after 5 years follow-up, based on USPHS evaluation; however, this study had methodological limitations, because there was no controls group with
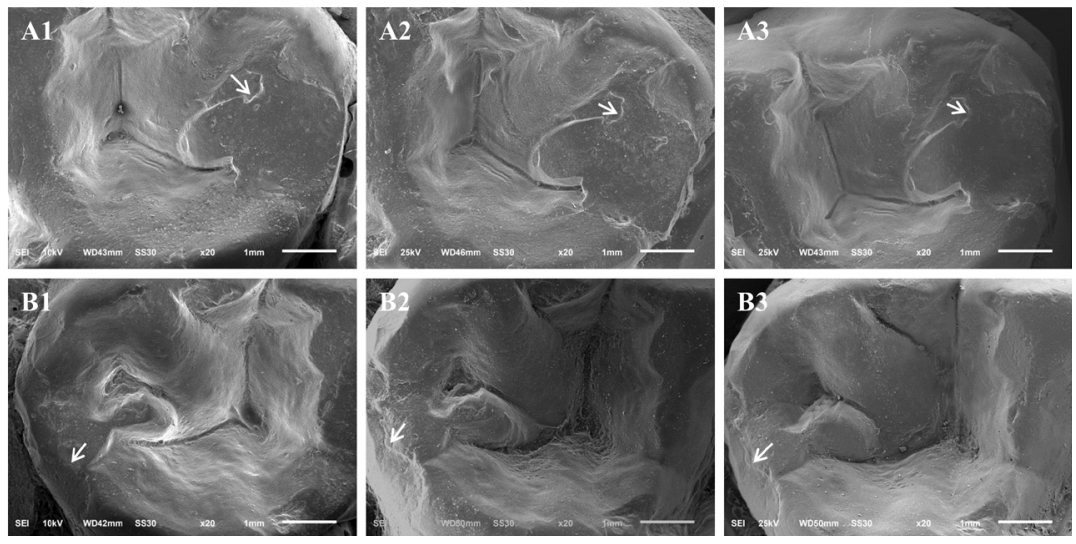

Figure 4. SEM on the Restorations Performed by Conventional Method (A) or Er:YAG laser (B). A1: initial restoration; A2: restoration after 6 months; A3: restoration after 12 months. B1: initial restoration; B2: restoration after 6 months; B3: restoration after 12 months. The arrow indicates the adhesive interface. 
drills. Franzon et $\mathrm{al}^{, 35}$ demonstrated that composite restorations conducted in primary molars showed the survival of $76 \%$ after 2 years follow-up, and the selective caries removal technique also resulted in less pulp exposure. In a randomized controlled trial comparing Er: YAG laser irradiation and rotary bur Sarmadi et al, ${ }^{36}$ showed no statistically significant differences between the restorations performed after excavation with the 2 methods, either in quality or survival of restorations using USPHS criteria ${ }^{26}$ over a 2 -year period.

With the purpose to analyze the presence of irregularities and gaps ${ }^{20}$ in the marginal sealing of the restoration, it was molded using addition-cured silicone ${ }^{37}$ and by means of epoxy resin model, it was possible to analyze the original characteristics of the restoration under $20 \times$ magnification. SEM analysis showed 10\% of gaps in the fullest extent of the restoration when the dentin caries removal was conducted with Er: YAG laser irradiation. Restorations performed by drills at low-speed showed $20 \%$ of gaps, located in the cavosurface angle of the proximal margin. These results demonstrated that both methods were effective because gaps were detected in a non-expressive amount of restorations according to Galafasi et al..$^{20}$

Er: YAG laser irradiation promotes a conservative treatment in dentin caries removal, ${ }^{38}$ moreover it does not produce noise, pressure or vibration, ${ }^{13,38}$ reducing the perception of pain during laser treatment, ${ }^{39}$ as well as decreases the need for the use of local infiltrative anesthesia. ${ }^{13,14}$ This technique is preferred in relation to bur preparation by patients $\mathrm{s}^{40}$ and is a potential alternative to mechanical drill.

\section{Conclusion}

- Salivary cortisol levels in children that received dentin caries removal using Er: YAG laser were similar to the control group.

- Class II restorations after selective removal of necrotic dentin in primary molars evaluated after 1 year period did not suffer interference by the use of Er: YAG laser irradiation.

- The accomplishment of a greater number of longitudinal clinical studies using salivary cortisol levels during Er: YAG laser irradiation for removal necrotic dentin as well the composite resin restorations performed should be investigated.

\section{Ethical Considerations}

The Research Ethics Committee of Ribeirão Preto School of Dentistry/ São Paulo University approved this study in this case number $(\# 21018413000005419)$. It was registered in the Brazilian Registry of Clinical Trials (ReBEC) (identifier: RBR-2t54nx).

\section{Conflict of Interests}

The authors declare no conflict of interest.

\section{Acknowledgments}

The authors would like to thank FAPESP for financial support (grant number \#2014/07942-4). Silmara Aparecida Milori Corona is grateful to $\mathrm{CNPq}$ for the research productivity scholarships (grants \#307520/20137). Silvana Aparecida Fernandes Polizeli is grateful to Coordination for the Improvement of Higher Education Personnel (CAPES) for the doctoral scholarship awarded.

\section{References}

1. O'Connell AC. The partial removal of carious tissue may arrest caries progression in primary teeth. J Evid Dent Pract. 2012;12(3);146-148. DOI: 10.1016/j.jebdp.2012.06.011

2. Ribeiro CC, de Oliveira Lula EC, da Costa RC, Nunes AM. Rationale for the partial removal of carious tissue in primary teeth. Pediatr Dent. 2012;34(1):39-41.

3. Kidd EAM. How 'clean' must a cavity be before restoration? Caries Res. 2004; 38(3):305-313. Doi: 10.1159/000077770

4. Montedori A, Abraha I, Orso M, D’Errico PG, Pagano S, Lombardo G. Lasers for caries removal in deciduous and permanent teeth. Cochrane Database Syst Rev. 2016;26;9, CD010229. Doi: 10.1002/14651858.CD010229.pub2

5. Yfanti K, Kitraki E, Emmanouil D, Pandis N, Papagiannoulis L. Psychometric and biohormonal indices of dental anxiety in children. A prospective cohort study. Stress. 2014;17(4):296-304. Doi: 10.3109/10253890.2014.918602

6. Keller U, Hibst R, Geurtsen W, Schilke R, Heidemann D, Klaiber B, Raab WH. Erbium: YAG laser application in caries therapy. Evaluation of patient perception and acceptance. J Dent. 1998;26(8):649-656.

7. Obulareddy VT, Chava VK, Nagarakanti S. Association of Stress, Salivary Cortisol, and Chronic Periodontitis: A Clinico-biochemical Study. Contemp Clin Dent. 2018;9(2):S299-S304.

8. Chaturvedi Y, Chaturvedy S, Marwah N, Chaturvedi S, Agarwal S, Agarwal N. Salivary Cortisol and Alphaamylase-Biomarkers of Stress in Children undergoing Extraction: An in vivo Study. Int J Clin Pediatr Dent. 2018;11(3):214-218.

9. Hanrahan K, McCarthy AM, Kleiber C, Lutgendorf S, Tsalikian E. Strategies for salivary cortisol collection and analysis in research with children. Appl Nurs Res. 2006;19(2):95-101. Doi: 10.1016/j.apnr.2007.04.009

10. Dušková M, Vašáková J, Dušková J, Kaiferová J, Broukal Z, Stárka L. The role of stress hormones in dental management behavior problems. Physiol Res. 2017;26 (3):S317-S322.

11. Polat C, Düzer S, Ayyıldız H, Seç S, Aksoy N, Sakallığlu Ö, Akyiğit A, Çetiner H. Association Between Anxiety, Depression, and Salivary Cortisol Levels in Patients with Recurrent Aphthous Stomatitis. Turk Arch Otorhinolaryngol. 2018;56(3):166-169. DOI: 10.5152/ tao.2018.3242

12. Tzira D, Prezerakou A, Papadatos I, Vintila A, Bartzeliotou A, Apostolakou F, Papassotiriou I, Papaevangelou V. Salivary biomarkers may measure stress responses in critically ill children. SAGE Open Med. 2018;25(6):2050312118802452. doi: $10.1177 / 2050312118802452$.

13. Keller U, Hibst R. Effects of Er:YAG Laser in caries treatment: a clinical pilot study. Lasers Surg Med. 
1997;20(1):32-38.

14. Krause F, Braun A, Lotz G, Kneist S, Jepsen S, Eberhard J. Evaluation of selective caries removal in deciduous teeth by a fluorescence feedback-controlled Er: YAG laser in vivo. Clin Oral Invest. 2008;12(3):209-215. Doi: $10.1159 / 000088186$

15. Pelagalli J, Gimbel CB, Hansen Rt, Swett A, Winn, DW. Investigational study of the use of EnYAG laser versus dental drill for caries removal and cavity preparation-Phase I. J Clin Laser Med Surg. 1997;15(3):109-115. DOI: 10.1089/clm.1997.15.109

16. Aoki A, Ishikawa I, Yamada T, Otsuki M, Watanabe H, Tagami J, Ando Y, Yamamoto H. Comparison between Er:YAG laser and conventional technique for root caries in vitro. J Dent Res. 1998;77(6):1404-1414. Doi: 10.1177/00220345980770060501

17. Hibst R, Keller U. Experimental studies of the application of the Er:YAG laser on dental hard subs-tances: I. Measurement of the ablation rate. Lasers Surg Med. 1989;9(4):338-334. PMID:

18. Guler C, Malkoc MA, Gorgen VA, Dilber E, Bulbul M. Effects of Er:YAG laser on mineral content of sound dentin in primary teeth. ScientificWorldJournal. 2014;2014:578342 doi: 10.1155/2014/578342.

19. Valério RA, Borsatto MC, Serra MC, Polizeli SA, Nemezio MA, Galo R, Aires CP, Dos Santos AC, Corona AS. Caries removal in deciduous teeth using an Er:YAG laser: a randomized split-mouth clinical trial. Clin Oral Invest. 2016;20(1):65-73. DOI: 10.1007/s00784-015-1470-z

20. Galafassi D, Scatena C, Galo R, Curylofo-Zotti FA, Corona SAM, Borsatto MC. Clinical evaluation of composite restorations in Er:YAG laser-prepared cavities re-wetting with chlorhexidine. Clin Oral Investig. 2017;21(4):12311241. Doi: 10.1007/s00784-016-1897-x

21. Haralabakis NB, Yiagtzis SC, Toutountzakis NM. Premature or delayed exfoliation of deciduous teeth and root resorption and formation. Angle Orthod. 1994;64(2):151-157. DOI: 10.1043/0003-3219(1994)064<0151:PODEOD>2.0.CO;2

22. Pereira-Santos D, Brêda-Júnior MA, Ferraz EP, Crippa GE, de Oliveira FS, da Rocha-Barros VM. Study comparing midazolam and nitrous oxide in dental anxiety control. J Craniofac Surg. 2013;24(5):1636-9. PMID: 24036742

23. Massara Ml, Alves JB, Brandao PR. Atraumatic restorative treatment: clinical, ultrastructural and chemical analysis. Caries Res. 2002;36(6):430-436. DOI: 10.1159/000066534

24. Maltz M, Oliveira EF, Fontanella V, Carminatti G. Deep caries lesions after incomplete dentine caries removal: 40-month follow-up study. Caries Res. 2007;41(6):493-496. DOI: $10.1159 / 000109349$

25. Pimenta RA, Penido CV, Cruz Rde A, Alves JB. Morphology of the dentin on primary molars after the application of phosphoric acid under different conditions. Braz Oral Res. 2010;24(3):323-328.

26. Cvar JF, Ryge G. Reprint of criteria for the clinical evaluation of dental restorative materials. 1971. Clin Oral Invest. 2005;9(4):215-232. doi: 10.1007/s00784-005-0018-Z

27. Akyuz S, Pince S, Hekin N. Children's stress during a restorative dental treatment: assessment using salivary cortisol measurements. J Clin Pediatr Dent. 1996;20(3):219223.

28. Farias S, Nemezio M, Corona S, Aires C, Borsatto M. Effects of low-level laser therapy combined with toluidine blue on polysaccharides and biofilm of Streptococcus mutans. Lasers Med Sci. 2016;31(5):1011-1016. Doi: 10.1007/ s10103-016-1944-5

29. Jessop DS, Turner-Cobb JM. Measurement and meaning of salivary cortisol: a focus on health and disease in children. Stress. 2008;11(1):1-14.

30. Kandemir S, Okşan T, Alpöz AR, Ergezer G, Kabalak T. Salivary cortisol levels in children during dental treatment. J Marmara Univ Dent Fac. 1997;2(4):639-642.

31. McCarthy AM, Hanrahan K, Kleiber C, Zimmerman MB, Lutgendorf S, Tsalikian E. Normative salivary cortisol values and responsivity in children. Appl Nurs Res. 2009;22(1):54-62.

32. Curcio WB, Abreu LG, Carrada CF, Ribeiro Scalioni FA, Ribeiro RA. Relationship Between Salivary Cortisol Levels and Children's Behavior During a Dental Examination. J Dent Child. 2017;84(2):80-85.

33. Samad-Zadeh A, Harsono M, Belikov A, Shatilova KV, Skripnik A, Stark P, Egles C, Kugel G. The influence of lasertextured dentinal surface on bond strength. Dent Mater. 2011;27(10):1038-1044. Doi: 10.1016/j.dental.2011.07.005

34. Hamidi MM, Ercan E, Dülgergil ÇT, Çolak H. Evaluation of the clinical success of class I cavities prepared by an Er:YAG laser-5-year follow-up study. Lasers Med Sci. 2017;30(7):1895-1901.

35. Franzon R, Opdam NJ, Guimarães LF, Demarco FF, Casagrande L, Haas AN, Araujo FB. Randomized controlled clinical trial of the 24-months survival of composite resin restorations after one-step incomplete and complete excavation on primary teeth. J Dent. 2015;43(10):12351241. Doi: 10.1016/j.jdent.2015.07.011

36. Sarmadi R, Andersson EV, Lingström P, Gabre P. A Randomized Controlled Trial Comparing Er:YAG Laser and Rotary Bur in the Excavation of Caries Patients' Experiences and the Quality of Composite Restoration. Open Dent J. 2018;31(12):443-454. DOI: 10.2174/1874210601812010443

37. Williams PT, Jackson DG, Bergman W. An evaluation of the time-dependent dimensional stability of eleven elastomeric impression materials. J Prosthet Dent. 1984;52(1):120-125.

38. Bohari MR, Chunawalla YK, Ahmed BM. Clinical evaluation of caries removal in primary teeth using conventional, chemomechanical and laser technique: an in vivo study. J Contemp Dent Pract. 2012;13(1):40-47.

39. Baraba A, Perhavec T, Chieffi N, Ferrari M, Anić I, Miletić I. Ablative potential of four different pulses of Er:YAG lasers and low-speed hand piece. Photomed Laser Surg. 2012;30(6):301-307. Doi: 10.1089/pho.2011.3190

40. Sarmadi R, Hedman E, Gabre P. Laser in caries treatment - patient's experiences and opinions. Int J Dent Hyg. 2014;12(1):67-73. doi: 10.1111/idh.12027 